\title{
Climate change impact on a groundwater-influenced hillslope ecosystem
}

\author{
R. J. Brolsma, ${ }^{1,2}$ M. T. H. van Vliet, ${ }^{2,3}$ and M. F. P. Bierkens ${ }^{1,2}$ \\ Received 17 October 2009; revised 24 April 2010; accepted 17 June 2010; published 2 November 2010.
}

[1] This study investigates the effect of climate change on a groundwater-influenced ecosystem on a hill slope consisting of two vegetation types, one adapted to wet and one adapted to dry soil conditions. The individual effects of changes in precipitation, temperature, and atmospheric $\mathrm{CO}_{2}$ concentration are compared to the combined effect of these factors. Change in atmospheric conditions is based on the Netherlands. Projected climate change is obtained from an ensemble of nested global and regional climate models (GCMs and RCMs), representing the Intergovernmental Panel on Climate Change Special Report on Emissions Scenarios A2 scenario for 2100. For each GCM-RCM combination, change factors were determined and transferred to a stochastic weather generator. All projections show higher temperatures and less annual precipitation. Simulations were performed using an ecohydrological model, consisting of a dynamic soil-plant-atmosphere-continuum model that is fully coupled to a variably saturated hydrological model, using the stochastic weather data as input. Model results show that increasing atmospheric $\mathrm{CO}_{2}$ concentration results in higher biomasses because of higher water use efficiency and a decrease in evaporation downslope where vegetation growth is light limited. The change in precipitation regime (drier summers, wetter winters) causes a decreased biomass of especially the dry-adapted species and increased upslope groundwater recharge, resulting in groundwater rise and an upward shift of wet-adapted vegetation. Temperature rise results in decreased biomass because respiration increases stronger than carbon assimilation, while increased transpiration causes drier soils and a prolonged period of water-limited growth. The combined effect is dominated by the increase in temperature and change in precipitation regime, causing decreased biomass throughout. Surprisingly, the effect on groundwater level depends on the degree by which precipitation distribution changes within the year, showing a drop at a small change and a rise when change is larger. This study thus shows that climate change effects on hydrology and vegetation are far from straightforward and call for fully coupled ecohydrological models and upslope-downslope interaction.

Citation: Brolsma, R. J., M. T. H. van Vliet, and M. F. P. Bierkens (2010), Climate change impact on a groundwater-influenced hillslope ecosystem, Water Resour. Res., 46, W11503, doi:10.1029/2009WR008782.

\section{Introduction}

[2] Global climate change projections for the 21 st century indicate a rise in air temperatures and a general increase in precipitation under increasing $\mathrm{CO}_{2}$ emissions. However, large regional differences occur, resulting in regions with a decrease in precipitation and a change in distribution of precipitation over the year [Solomon et al., 2007]. Field studies and experiments have shown that vegetation reacts in a complex way to climate change and atmospheric $\mathrm{CO}_{2}$ rise, working at different spatial and temporal scales.

\footnotetext{
${ }^{1}$ Department of Physical Geography, Utrecht University, Utrecht, Netherlands.

${ }^{2}$ Deltares, Utrecht, Netherlands.

${ }^{3}$ Earth System Science and Climate Change, Wageningen University and Research Centre, Wageningen, Netherlands.

Copyright 2010 by the American Geophysical Union. 0043-1397/10/2009WR008782
}

[3] At the scale of individual plants physiological responses will occur. Increased atmospheric $\mathrm{CO}_{2}$ concentration will result in a reduction of stomatal conductance [e.g., Medlyn et al., 2001; Kruijt et al., 2008], causing a decrease in transpiration of plants. However, at the same time the increase in $\mathrm{CO}_{2}$ will cause higher carbon assimilation rates and net primary production (NPP), resulting in a higher biomass, which increases transpiration. Studies to this effect are however most often based on short measurement periods on young trees. Long-term effects on tree species remain unclear, also because the interactions with other limiting factors like nutrients and water availability are not well known [Karnosky, 2003].

[4] Change in rainfall regime results in change in soil moisture conditions. This in turn will influence (fine) root growth and growth of mycorrhiza and therefore root water uptake. The effect of temperature rise will affect vegetation physiologically by increasing biochemical activity. Therefore carbon assimilation is expected to increase, but at the same time respiration is expected to increase as well. The 
net effect on vegetation growth remains unclear and will also depend on other environmental conditions [Saxe et al., 2001]. At higher temperatures also the phenology will be affected, prolonging the growing season and therefore carbon assimilation, respiration, transpiration and interception evaporation alike. However, the reaction of phenology is uncertain itself, as the true mechanisms are still not understood. For instance the relation between phenology and day length is strong as well [Saxe et al., 2001].

[5] Individual trees react to all of the above changes in atmospheric conditions and resulting changes in soil conditions by changing their growth form, e.g., by increasing the amount of root mass relative to the above ground biomass as a reaction to water stress. At larger spatial scales shifts in the zonation of vegetation are expected to occur. These shifts are connected to temperature rise and changes in precipitation. Global vegetation models show vegetation zones to shift toward the poles and on local scales to higher altitudes. Landscape scale models show that changes in precipitation result in shifts in the soil moisture regime, which will cause drought tolerant and wet tolerant species to shift upslope and downslope [Brolsma and Bierkens, 2007].

[6] It can be concluded that the effect of climate change is difficult to investigate in field experiments because of the long response time of vegetation systems to change in environmental conditions. Also geographical substitution to investigate climate change has limitations, because it is difficult to extract the individual effect of change of a climate variable, as a consequence of simultaneous change in other environmental conditions.

[7] Using computer models can help understand and predict the reaction of ecohydrological systems to climate change. The nonlinearities in the reaction of vegetation to climate change show the importance of using a biophysically based vegetation models. The majority of modeling studies that have been performed to assess the influence of climate change on ecohydrological systems focus on a large (global) scale [e.g., Friend et al., 1997; Prentice et al., 1993; Sitch et al., 2003]. These models however omit many local interactions and feedbacks, such as competition for light and local-scale variations in soil moisture and groundwater, although vegetation competition is sometimes included using Lotka Volterra type equations [e.g., Arora and Boer, 2006]. Hydrological models tend to simplify vegetation dynamics and conversely in ecological models hydrological processes are often over simplified, with Band et al. [1993] as a notable exception.

[8] The effect of climate change on hydrological systems is thus far from straightforward. It depends heavily on how vegetation reacts to changes in precipitation, temperature and atmospheric $\mathrm{CO}_{2}$ concentration. Changes in vegetation affect the hydrological system because of changes in interception evaporation and transpiration, while changes in hydrology feedback on vegetation [Eagleson, 1978]. A sound analysis of hydrological sensitivity to climate change thus demands a coupled vegetation-hydrology approach, i.e., ecohydrological models [Rodriguez-Iturbe, 2000].

[9] Up to now, most ecohydrological models treating both vegetation functioning as well as hydrological processes in a fully coupled mode, are tailored to water-limited systems [Rodriguez-Iturbe and Porporato, 2004]. However, in temperate climate zones groundwater can have a strong effect on the reaction of vegetation to climate change, because it strongly influences the spatial temporal distribution of soil moisture and therefore water and oxygen stress of vegetation.

[10] Including groundwater dynamics in these models is therefore of great importance [Daly et al., 2009; RodriguezIturbe et al., 2007] and especially spatial dynamics allowing for lateral groundwater flow [Brolsma et al., 2010a].

[11] Here we aim to show the effect of climate change on a temperate forest ecosystem using a fully coupled hydrologicalvegetation model. To account for most of the above mentioned nonlinearities in the reaction of vegetation to climate change and be able to investigate multiple aspects of climate change, we use a biophysically based vegetation model. The resulting ecohydrological model includes light competition between two tree species with different toleration to water and oxygen stress. We particularly focus on the individual effect of temperature, precipitation and $\mathrm{CO}_{2}$ change and how these compare to the effect of the combination of these factors. Climate input results from 8 regional climate model (RCM) experiments from the PRUDENCE project for current and future (2071-2100) climate under the Intergovernmental Panel on Climate Change (IPCC) Special Report on Emissions Scenarios (SRES) A2 scenario [Nakicenovic and Swart, 2000]. The output of these models is further downscaled using a stochastic rainfall model and weather generator. The hydrological part consists of a hillslope model including lateral groundwater flow. This way we represent the higher (drier) and lower (wetter) parts of the landscape and their connection through the groundwater system.

\section{Methods}

[12] In this study we use a fully coupled vegetation and variably saturated hydrological model. The vegetation model has been described in detail by Brolsma et al. [2010b], and the hydrological model has been described by Brolsma et al. [2010a]. Climate change scenarios, used as input into the coupled ecohydrological model, have been generated by applying change factors from a selection of RCM experiments of the PRUDENCE project, which were downscaled to local atmospheric forcing using a stochastic rainfall model [Burton et al., 2008] in combination with the stochastic weather generator of Richardson [1981].

\subsection{Hydrological Model}

[13] A first full description of the hydrological model, that only included percolation in the unsaturated zone as gravitational flow can be found in work by van Beek [2002]. Modifications to include matric potential driven unsaturated flow including capillary rise are given by Brolsma et al. [2010a]. We assume a shallow unconfined aquifer with noflow boundaries along the borders. This means that water can only leave the system through exfiltration, after which water is instantly removed as runoff from surface of the system. Also infiltration access runoff is instantly removed from the system. The model (Figure 1) consists of three variably saturated layers in which the groundwater level can fluctuate. Lateral fluxes are limited to the saturated zone and vertical fluxes are limited to the unsaturated zone and unsaturatedsaturated interface. The vertical Darcy fluxes in the unsaturated zone are based on soil matric potential and unsaturated conductivity, where both depend on soil moisture content 


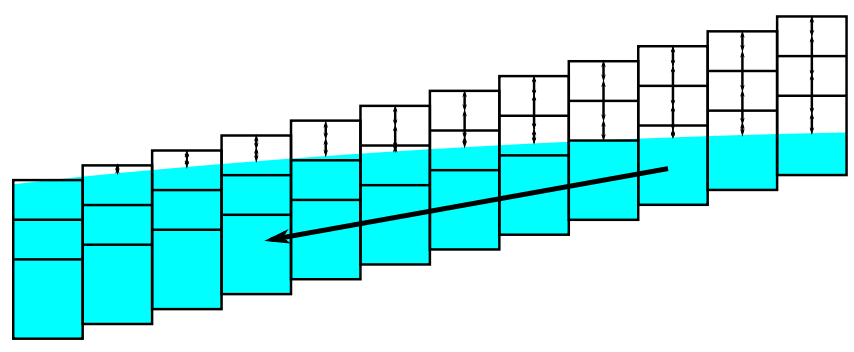

Figure 1. Simplified representation of the hillslope, the aquifer, and the groundwater.

using van Genuchten [1980] equations. To increase the numeric stability of the model and allowing relatively large time steps, every time step the equilibrium soil moisture content of the layers was calculated based on the layer above. Within one calculation time step a cell that is wetter than the equilibrium soil moisture content cannot get drier than its equilibrium soil moisture content, and vice versa for cells that are drier then the equilibrium soil moisture content. The horizontal fluxes are modeled with Darcy's equation in two dimensions.

\subsection{Vegetation Model}

[14] A full description of the vegetation model is given by Brolsma et al. [2010b]. Here only a brief description is given of the main assumptions and equations. The vegetation model is two dimensional and is grid based, having square cells of $100 \mathrm{~m}^{2}$, corresponding to the surface area of the footprint of a mature tree. The model uses plant functional types, that are assumed to be always present at least at a primordial biomass in all cells (i.e., no dispersal modeled). The vegetation model runs on a half-hourly time step for the calculation of transpiration, carbon assimilation and respiration. However, to produce long-time (century) runs the model is upscaled to daily time steps (see section 2.2.1).

\subsubsection{Transpiration, Carbon Assimilation, and Respiration}

[15] Simulation of transpiration and carbon assimilation is based on work by Daly et al. [2004], which is in turn (for the carbon assimilation part) strongly based on the model of Farquhar et al. [1980]. Transpiration of vegetation is assumed to be an equilibrium between atmospheric demand and the capacity of the vegetation to provide water to the leaves for transpiration. Atmospheric demand is calculated based on the Penman-Monteith equation [Monteith, 1965]:

$$
E T_{p m}=\frac{\left(\lambda_{w} \gamma_{w} g_{b a} \rho_{a} D+\Delta A R\right)}{\rho_{w} \lambda_{w}\left[\gamma_{w}\left(\frac{g_{b a}}{g_{s} L A I}+1\right)+\Delta\right]},
$$

where $A R\left[\mathrm{~W} \mathrm{~m}^{-2}\right]$ is the absorbed radiation, $D[-]$ the atmospheric vapor pressure deficit, $g_{s}\left[\mathrm{~m} \mathrm{~s}^{-1}\right]$ the stomatal conductance, $\lambda_{w}\left[\mathrm{~J} \mathrm{~kg}^{-1}\right]$ the latent heat of water vaporization, $\gamma_{w}\left[\mathrm{~Pa} \mathrm{~K}^{-1}\right]$ the psychrometer constant, $\Delta\left[\mathrm{Pa} \mathrm{K}^{-1}\right]$ the slope of the saturated water vapor pressure to temperature relationship, $\rho_{w}\left[\mathrm{~kg} \mathrm{~m}^{-3}\right]$ the water density, $\rho_{a}\left[\mathrm{~kg} \mathrm{~m}^{-3}\right]$ the air density, $L A I[-]$ the leaf area index and $g_{b a}\left[\mathrm{~m} \mathrm{~s}^{-1}\right]$ is the series of conductances of the boundary layer and the atmosphere. Note that $D$ and $\Delta$ are both functions of temperature.
[16] Stomatal conductance is modeled using the Jarvis [1976] approach, where $g_{s}$ depends on $g_{s, \text { max }}$ through a series of reduction functions related to radiation $(R a d)$, vapor pressure deficit $(D)$, leaf temperature $\left(T_{l}\right)$,atmospheric carbon concentration $\left(\mathrm{CO}_{2}\right)$ and leaf water potential $\left(\psi_{l}\right)[\mathrm{Pa}]$. The reduction of $g_{s}$ due to large negative leaf water potentials is modeled as

$$
f_{\psi_{l}}\left(\psi_{l}\right)= \begin{cases}0 & \text { if } \psi_{l}>\psi_{l_{0}} \\ \frac{\psi_{l}-\psi_{l_{0}}}{\psi_{l_{1}}-\psi_{l_{0}}} & \text { if } \psi_{l_{0}}<\psi_{l}<\psi_{l_{1}} \\ 1 & \text { if } \psi_{l}<\psi_{l_{1}},\end{cases}
$$

where $\psi_{l_{1}}[\mathrm{~Pa}]$ is the threshold potential at which the rootto-leaf hydraulic conductance begins to decline, $\psi_{l_{0}}[\mathrm{~Pa}]$ threshold potential at which the root-to-leaf hydraulic conductance becomes negligible.

[17] The dependence of $g_{s}$ to atmospheric $\mathrm{CO}_{2}$ is based on work by Kruijt et al. [2008], who determined a decrease in stomatal conductance for woody species of $0.068 \%$ per $1 \mathrm{ppm}$ increase in atmospheric $\mathrm{CO}_{2}$ concentration.

[18] The plants capacity provide water to the leaves is given by

$$
E T_{s r p}=g_{s r p}\left(\psi_{s}-\psi_{l}\right),
$$

where $g_{s r p}\left[\mathrm{~m} \mathrm{~Pa}^{-1} \mathrm{~s}^{-1}\right]$ is the soil-root-plant conductance and $\psi_{s}[\mathrm{~Pa}]$ the soil water potential. $g_{s r p}$ depends on the matric potential and unsaturated conductivity of the soil and the leaf water potential [Daly et al., 2004].

[19] In wet soil moisture conditions, root water uptake can be limited because of a shortage of oxygen in the root zone. To account for this effect, a reduction function $f_{o x}$, that limits the soil root conductance, is used [Feddes et al., 1978; Brolsma et al., 2010b]:

$$
f_{o x}= \begin{cases}1 & \text { if } \theta<\theta_{o x, 1} \\ \frac{\theta_{o x, 0}-\theta}{\theta_{o x, 0}-\theta_{o x, 1}} & \text { if } \theta_{o x, 1}<\theta<\theta_{o x, 0} \\ 0 & \text { if } \theta>\theta_{o x, 0},\end{cases}
$$

where $\theta[-]$ is the root zone soil moisture content $\theta_{o x, 1}[-]$ is the soil moisture content at which root water uptake starts to decline and $\theta_{o x, 0}[-]$ is the soil moisture content at which the root water uptake stops. Root water uptake is also sensitive to soil temperature as a consequence of respiration reduction [Bartholomeus et al., 2008]. This effect has not been included in this model.

[20] Assuming steady states, atmospheric demand and the plants capacity to provide water to the leaves is in equilibrium. By solving for $\psi_{l}$ and $g_{s}$ such that $E T_{s r p}=E T_{p m}$ gives the actual transpiration.

[21] Carbon assimilation is based on the equilibrium between the $\mathrm{CO}_{2}$ flux from the atmosphere through the stomata to the intercellular spaces in the leaf $A_{n, g s b a}\left[\mathrm{~mol} \mathrm{~m}^{-2} \mathrm{~s}^{-1}\right]$ and biochemical demand for $\mathrm{CO}_{2}$ for photosynthesis $A_{n, b i o}$ $\left[\mathrm{mol} \mathrm{m}{ }^{-2} \mathrm{~s}^{-1}\right] . A_{n, g s b a}$ depends on stomatal conductance and the gradient in carbon concentration:

$$
A_{n, g_{s b a}}=g_{s b a, C O 2}\left(C_{a}-C_{i}\right),
$$


where $g_{s b a, C O 2}\left[\mathrm{~mol} \mathrm{~m} \mathrm{~m}^{-2} \mathrm{~s}^{-1}\right]$ is the series of stomatal, leaf boundary layer and aerodynamic conductances for $\mathrm{CO}_{2}$, $C_{a}\left[\mathrm{~mol} \mathrm{~mol}^{-1}\right]$ is the carbon concentration at the leaf surface and $C_{i}\left[\mathrm{~mol} \mathrm{~mol}^{-1}\right]$ is the intercellular carbon concentration.

[22] $A_{n, b i o}$ depends on radiation, leaf temperature and leaf water potential:

$$
A_{n, b i o}=A_{n, \psi_{l}} \min \left(A_{n, c}, A_{n, q}\right)
$$

where $A_{n, \psi_{l}}$ [-] is a reduction function for carbon assimilation due to low leaf water potential $\left(\psi_{l}\right)$ and $A_{n, c}\left[\mathrm{~mol} \mathrm{~m}^{-2} \mathrm{~s}^{-1}\right]$ and $A_{n, q}\left[\mathrm{~mol} \mathrm{~m}^{-2} \mathrm{~s}^{-1}\right]$ are the rubisco-limited and the light-limited carbon assimilation rate, respectively.

[23] The reduction of carbon assimilation due to low $\psi_{l}$ is modeled by

$$
A_{n, \psi_{l}}= \begin{cases}0 & \text { if } \psi_{l}<\psi_{l, A_{n, 0}} \\ \frac{\psi_{l}-\psi_{l, A_{n, 0}}}{\psi_{l, A_{n, 1}}-\psi_{l, A_{n, 0}}} & \text { if } \psi_{l, A_{n, 0}}<\psi_{l}<\psi_{l, A_{n, 1}} \\ 1 & \text { if } \psi_{l}>\psi_{l, A_{n, 1}},\end{cases}
$$

in which $\psi_{A n, 1}[\mathrm{~Pa}]$ is the threshold potential at which assimilation reduction caused by chemical action begins to decline and $\psi_{A n, 0}[\mathrm{~Pa}]$ is the threshold potential at which assimilation reduction caused by chemical action becomes negligible.

[24] The light-limited carbon assimilation rate is given by

$$
A_{n, q}=\frac{J}{4} \frac{C_{i}-\Gamma^{*}}{C_{i}+2 \Gamma^{*}},
$$

where $J$ [mol photons $\left.\mathrm{m}^{-2} \mathrm{~s}^{-1}\right]$ is the incident electron flux resulting from absorbed photosynthetically active radiation (APAR) and $\Gamma^{*}\left[\mathrm{~mol} \mathrm{C} \mathrm{mol}{ }^{-1}\right.$ air $]$ is the $\mathrm{CO}_{2}$ compensation point.

[25] In rubisco-limited conditions carbon assimilation is calculated by

$$
A_{n, c}=V_{c, \max } \frac{C_{i}-\Gamma^{*}}{C_{i}+K_{c}\left(1+o_{i} / K_{o}\right)},
$$

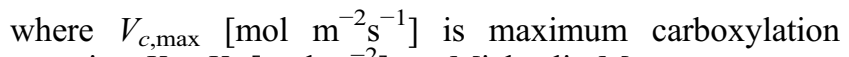
capacity, $K_{c}, K_{o}\left[\mathrm{~mol} \mathrm{~m}^{-2}\right]$ are Michaelis-Menten constants for $\mathrm{CO}_{2}$ and $\mathrm{O}_{2}$, respectively, and $o_{i}\left[\mathrm{~mol} \mathrm{~m}^{-2}\right]$ is atmospheric oxygen concentration. $V_{c, \max }, J, \Gamma$ and $K_{c}$ and $K_{o}$ all depend on leaf temperature,which is obtained from closing the energy balance. Once $g_{s}$ and $\psi_{l}$ are known from the calculation of $E T, A_{n}$ can be calculated solving $\mathrm{A} n_{g s b a}\left(C_{i}\right)=$ $A n_{\text {bio }}\left(C_{i}\right)$ for $C_{i}$.

[26] To perform long simulation runs ( $>100$ years), the vegetation model that runs on a time scale of half an hour, has to be upscaled to be used at daily time steps. During the day, meteorological parameters such as radiation, temperature and water vapor pressure deficit vary while they influence transpiration $(E T)$ and carbon assimilation $\left(A_{n}\right)$ in a nonlinear way. Therefore a simple linear upscaling using daily average values of the input variables leads to biased results. On a daily time scale seven variables influence $E T$ and $A_{n}: T_{\min }$ (minimum day temperature), $T_{\max }$ (maximum day temperature), Rad (incoming short-wave radiation), $\delta$ (day length), $n / N$ (time fraction cloud coverage), $\theta$ (root zone soil moisture content) and $L A I$. The range in values of each of these variables is discretized in steps (5-22 steps per variable). Half hourly values of ET based on equations (1) and (3) and $A_{n}$ based on equations (5) and (6) are calculated, where at each half-hourly time step the daily course of $T$ and $\mathrm{Rad}$ is accounted for. These half-hourly values of $E T$ and $A_{n}$ are summed to daily values and stored in a two separate lookup tables, for all possible combinations of the above mentioned seven variables between reasonable bounds. When performing long runs, daily values of $T_{\min }, T_{\max }$, $\operatorname{Rad}, \delta, n / N, \theta$ and $L A I$ are generated or calculated and the associated $E T$ and $A_{n}$ are then directly read from these lookup tables.

[27] Respiration of vegetation depends on biomass that is located in the different compartments of the vegetation (above and below ground woody biomass, leaves and fine roots) and the nitrogen content and temperature of the different compartments. The dependence of respiration on temperature is calculated using a modified Arrhenius equation (Lloyd and Taylor (1994), as cited by Sitch et al. [2003]):

$$
f(T)=\exp \left[308.56\left(\frac{1}{56.02}-\frac{1}{T+46.02}\right)\right]
$$

where $T\left[{ }^{\circ} \mathrm{C}\right]$ is the temperature of the compartment.

[28] Finally, carbon assimilate available for growth is defined as

$$
A_{n, \text { growth }}=\left(A_{n}-\text { Resp }_{\text {maint }}\right) \cdot 0.7
$$

where Resp $p_{\text {maint }}\left[\mathrm{mol} \mathrm{m} \mathrm{m}^{-2}\right]$ is the maintenance respiration calculated according to Sitch et al. [2003] and depending on $T$ according to (10) and 0.7 is a factor to account for respiration as a result of growth itself. Brolsma et al. [2010b] compared model simulations of daily, and yearly time scale to observations of $\mathrm{CO}_{2}$ and $\mathrm{H}_{2} \mathrm{O}$, showing good results.

[29] As the studied ecosystem consists of deciduous trees, phenology is included in the model. Phenology is based on the 10 day sum of maximum temperature. When this 10 day sum is larger than $100^{\circ} \mathrm{C}$ leaves and fine roots start to grow. When the sum is smaller than $100^{\circ} \mathrm{C}$ after having reached the full $L A I$ leaves and fine roots start to be shed. Leaf and root growth and shedding occur at a fixed rate depending on the $L A I$ and are included in the carbon balance of the vegetation. To model vegetation growth, it is assumed that $A_{n \text {,growth }}$ is first moved to the storage compartment, which is a fixed fraction of the sapwood of the wooden parts of the tree. When this compartment is full, excess $A_{n \text {,growth }}$ is used for biomass growth. Carbon for leaf and fine root growth are obtained from the storage until a minimum of $10 \%$ of carbon in the storage compartment is reached. The last $10 \%$ of the carbon storage can only be used for maintenance respiration. When the storage becomes empty, it is assumed that the tree dies. Tree height and maximum $L A I$ are directly related to biomass through allometric functions [Brolsma et al., 2010b]. The relation between above and below ground biomass is fixed in this model, which means that water or oxygen stress do not affect the growth form of the tree. For simplicity we assume a uniform root distribution within a fixed root zone of $0.6 \mathrm{~m}$ depth. As a consequence the vegetation is not able to adapt to shallow groundwater tables by increasing its root density in the unsaturated part of the 
Table 1. Parameters of the Plant Functional Type Adapted to Wet and the Plant Functional Type Adapted to Dry Conditions

\begin{tabular}{|c|c|c|c|}
\hline Parameter & Description & Wet Species & Dry Species \\
\hline$\psi_{0}$ & leaf water potential below which $g_{s}$ becomes $0[\mathrm{~Pa}]$ & $-0.45 \mathrm{e}+06$ & $-4.5 \mathrm{e}+06$ \\
\hline$\psi_{1}$ & leaf water potential below which $g_{s}$ starts to decline [Pa] & $-0.005 \mathrm{e}+06$ & $-0.05 \mathrm{e}+06$ \\
\hline$\psi_{a, 0}$ & leaf water potential below which assimilation becomes $0[\mathrm{~Pa}]$ & $-0.45 \mathrm{e}+06$ & $-4.5 \mathrm{e}+06$ \\
\hline$\psi_{a, 1}$ & leaf water potential below which assimilation starts to decline $[\mathrm{Pa}]$ & $-0.05 \mathrm{e}+06$ & $-0.5 \mathrm{e}+06$ \\
\hline$O_{x, 0}$ & soil moisture content above which root water uptake starts to decline [-] & $\theta_{\text {sat }}-0.03$ & $\theta_{\text {sat }}-0.10$ \\
\hline$O_{x, 1}$ & soil moisture content above which root water uptake becomes $0[-]$ & $\theta_{\text {sat }}-0.01$ & $\theta_{\text {sat }}-0.05$ \\
\hline
\end{tabular}

root zone, or to adapt to deeper groundwater tables by rooting deeper to reach the groundwater.

\subsubsection{Interception}

[30] Assuming a homogeneous canopy within a cell for each species, transmission and therefore interception of light within the canopy are modeled according to Beer's law for light absorption $\left(1-e^{-k L A I}\right)$. Light interception mainly depends on tree height and $L A I$, where both are a function of biomass of the individual vegetation type. Both height and $L A I$ increase with biomass. Precipitation interception is modeled as a bucket model. A gap fraction of the canopy, is used to determine direct through fall, and indirect through fall occurs when the maximum interception capacity is exceeded or if the precipitation amount is larger than the potential daily canopy evaporation, based on Penman's open water evaporation.

\subsubsection{Competition and Mortality}

[31] Vegetation competition is only local in the sense that there is only competition for light and water within a grid cell. Light competition is determined by tree height and $L A I$, where trees with a higher biomass are taller and have a higher $L A I$ and thus catch more light. Competition for water is determined by the plants reaction to large negative leaf water potentials and root water uptake parameters. There are no explicit spatial interactions between cells; only implicit through groundwater flow. A low soil moisture content can cause a large negative leaf water potential, $\psi_{l}[\mathrm{~Pa}]$. This causes cavitation, that leads to lower plant water conductance and therefore lower leaf water potential, lower stomatal conductance, and lower transpiration and carbon assimilation. The parameters that control the reaction of plant conductance and assimilation rate to leaf water potential differ between the species (Table 1).

[32] At high soil moisture contents oxygen stress occurs. As a result of oxygen stress root water uptake is hampered, causing again low leaf water potentials. The parameters controlling the root water uptake function at high moisture contents differ between species as well (Table 1).

[33] There are two causes of death for vegetation. First of all, vegetation dies when the carbon storage compartment is empty as described above. Secondly, vegetation can die as a consequence of disease, lightning, etc., which is modeled as a stochastic process with a probability of $1 / 300$ per year. Dispersal of vegetation is not included in the model and regrowth of vegetation after death of one vegetation type is based on the concept that a seed bank is present; that is, when a tree dies, the species starts regrowing the next time step at primordial biomass.

\subsection{Weather Generator}

[34] The vegetation model uses the following daily atmospheric input variables: precipitation amount, minimum and maximum temperature $\left(T_{\min }\right.$ and $\left.T_{\max }\right)$ and net long and incoming short (Rad) wave radiation. Time series of these variables are generated as a stochastic process. Precipitation is simulated using the stochastic rainfall model RainSim V3 [Burton et al., 2008] in which multisite time series are sampled from the spatial-temporal Neyman-Scott rectangular pulses process (STNSRP) [Kilsby et al., 2007; Cowpertwait, 1995]. Minimum and maximum temperature and clear sky short-wave radiation are generated using the Richardson [1981] weather generator and the dependence of long- and short-wave radiation to cloudiness are based on random sampling of historic cloud cover data [Brolsma et al., 2010b].

[35] The baseline run of rainfall is based on the statistical properties of meteorological measurements of the current climate (1961-1990) of 22 stations around Eindhoven. These statistical properties of the rainfall have subsequently been used to generate artificial rainfall series using the RainSimV3 rainfall model [Burton et al., 2008]. A more detailed description of the generated rainfall series that are used in our study, is given by M. T. van Vliet et al. (A multi-model ensemble of downscaledclimate change scenarios for the Dommel catchment, The Netherlands, submitted to Climate Research, 2010).

[36] The generated rainfall series were used as input for the weather simulator by Richardson [1981]. Usually this simulator determines the occurrence of wet and dry days based on a Markov chain process that is part of the simulator, but in this case we did not use this part of the model and used the simulated wet and dry days and daily rainfall on wet days from the STNSRP model as given.

[37] Parameterization and simulation of the Richardson generator then proceeded as follows. First, for each month mean minimum temperature $\left(T_{\min }\right)$ and mean maximum temperature $\left(T_{\max }\right)$ are determined for wet and dry days. Next, cross-covariances of residuals of minimum and maximum temperature are determined separately for each month and conditional to having a wet or a dry day. Conditional to month and having a wet or a dry day, a multivariate normal distribution of $T_{\min }$ and $T_{\max }$ is assumed to simulate their residuals and add them to the monthly means. Vapor pressure deficit is then estimated from $T_{\min }$ and $T_{\max }$ assuming dewpoint temperature $T_{d e w}$ to be equal to $T_{\min }$ according to relationships summarized by Allen et al. [1998]. Short-wave radiation is reduced based on cloudiness, which is, together with atmospheric temperature and vapor pressure deficit, used to calculate net incoming long-wave radiation [Shuttleworth, 1993].

[38] To simulate cloudiness, cloud cover data for the period 1961-1990 were divided into bins based on month number, rainfall amount and the difference between daily minimum and maximum temperature. Based on month number and predicted rainfall amount and the difference between daily 
Table 2. Main Characteristics of the Baseline Run and the Climate Change Scenarios ${ }^{\mathrm{a}}$

\begin{tabular}{lccccc}
\hline \multicolumn{1}{c}{ Name } & Period & RCM & GCM & Precipitation & Temperature \\
\hline Baseline & $1961-1990$ & & data & 777 & 9.7 \\
Arpege & $2071-2100$ & Arpege & HadCM3 & 759 & 12.8 \\
HAD-H-P & $2071-2100$ & HadRM3P & HadAM3P & 682 & 13.7 \\
HIRHAM-E & $2071-2100$ & HIRHAM & ECHAM4/OPYC & 710 & 14.6 \\
HIRHAM-H & $2071-2100$ & HIRHAM & HadAM3H & 709 & 13.2 \\
RACMO-H & $2071-2100$ & RACMO & ECHAM4/OPYC & 716 & 13.0 \\
RCAO-E & $2071-2100$ & RCAO & HadAM3H & 734 & 13.4 \\
RCAO-H & $2071-2100$ & RCAO & HadAM3H & 750 & 12.9 \\
REMO-H & $2071-2100$ & REMO &
\end{tabular}

${ }^{a}$ Name denotes the name of the scenario used in this article, Period is the time interval for which the rainfall generator has been calibrated, RCM is the regional climate model that has been used to force the rainfall generator [Burton et al., 2008] and weather generator [Richardson, 1981], GCM is the general circulation model that has been used as boundary condition for the RCM, Precipitation (mm) is the sum of annual precipitation, and Temperature $\left({ }^{\circ} \mathrm{C}\right)$ is the mean annual temperature. 0.3 .

minimum and maximum temperature cloud cover percentages are drawn randomly from the corresponding bin.

\subsection{Climate Change Scenario Runs}

[39] To simulate the effect of climate change we focus on the SRES A2 emission scenario of the IPCC for the period 2071-2100, which describes a very heterogeneous world with continuously increasing global population and regionally oriented economic growth [Nakicenovic and Swart, 2000]. A selection of GCM (general circulation model) and RCM (regional climate model) combinations for the A2 scenario that were generated within the PRUDENCE project [Christensen et al., 2007] were used. The climate change scenarios are based on both the statistical properties of the baseline run and on the monthly changes in statistics calculated from the outputs of the selected GCM-RCM experiments between the baseline period (1961-1990) and future period (2071-2100). In the PRUDENCE project output of several GCMs, forced with the A2 emission scenario, were selected to serve as boundary condition for different RCM runs. An overview of the selected GCM-RCM combinations used in our study is given in Table 2. Boundary conditions of the GCMs HadAM3 and ECHAM4/OPYC have both been used for the runs with the RCMs HIRHAM and RCAO. The RCMs were also run based on the output of a GCM under current climate conditions to produce a baseline run.

[40] Based on differences of the RCM output of the baseline run (1961-1990) and the scenario runs (2071-2100), change factors for mean rainfall, daily rainfall variance, daily skewness coefficient, Pdry (proportion of dry days), daily rainfall lag-1 autocorrelation and mean temperature were determined for each month. A procedure using change factors [Kilsby et al., 2007; Fowler et al., 2007] is followed because the RCMs do not sufficiently well reproduce meteorological conditions on short time scales. These changes were then forced on the calculated monthly statistics of the calibrated rainfall model for the selected rainfall gauges around Eindhoven for the actual situation (van Vliet et al., submitted manuscript, 2010). The time series of one location (station Eindhoven) were used as input for the ecohydrological model; that is, no spatial fields were used.

[41] The changes in mean temperature per month, based on the RCM outcomes, were added to the average monthly $T_{\min }$ and $T_{\max }$ assuming both to change at the same rate and the variance to remain the same. The cross covariances of
$T_{\min }$ and $T_{\max }$ residuals were, for a wet and a dry day, assumed to remain constant, as well as the statistical parameters for cloudiness for a given vapor pressure deficit, $T_{\min }$ and $T_{\max }$ and for wet and dry days.

[42] In all the scenarios the temperature is projected to increase. From Figure 2 it can be seen that average annual temperature is expected to rise from $9.7^{\circ} \mathrm{C}$ to $12.8-15.1^{\circ} \mathrm{C}$. The average temperature increase in winter is around $3{ }^{\circ} \mathrm{C}$ and in summer around $5^{\circ} \mathrm{C}$. The RCM runs that are based on the boundary conditions of the ECHAM4/OPYC GCM (HIRHAM-E, RCAO-E) show a larger temperature increase than the ones based on the HadAM3H GCM (HIRHAM-H, $\mathrm{RCAO}-\mathrm{H})$.

[43] Average annual precipitation is projected to decrease from a present-day $777 \mathrm{~mm} \mathrm{yr}^{-1}$ to $759-682 \mathrm{~mm} \mathrm{yr}^{-1}$. As can be seen in Figure 2 precipitation in summer will decrease, while it increases in winter. This change in precipitation is mainly caused by a decrease in the number of days that it rains, as the amount of rain on rainy days slightly increases all year round. The Had-H-P has the lowest annual rainfall amount. The RCM runs that are based on the ECHAM4/ OPYC GCM show a larger change in seasonal precipitation pattern (larger increase in winter and larger decrease in summer) than the RCM runs based on the HadAM3 GCM.

[44] For the baseline run the atmospheric $\mathrm{CO}_{2}$ concentration is set at $370 \mathrm{ppm}$. For the period 2071-2100 the $\mathrm{CO}_{2}$ concentration is assumed to be $730 \mathrm{ppm}$ for all scenarios and is based on the IPCC SRES A2 emission scenarios [Nakicenovic and Swart, 2000].

\subsection{Model Setup}

[45] For this study the hydrological model uses in plan view square cells of $100 \mathrm{~m}^{2}$. The thickness of the layers of the hydrological model are from top to bottom of 1,2 and $5 \mathrm{~m}$, resulting in an aquifer thickness of $8 \mathrm{~m}$. The slope is 50 cells long and 100 cells wide with a slope of $5 \%$. The soil texture is homogeneous and consists of sandy loam (van Genuchten parameters: $\theta_{\text {sat }}=0.41, \theta_{r}=0.065, K_{s}=$ $1.06 \mathrm{~m} \mathrm{~d}^{-1}, \alpha=7.5 \mathrm{~m}^{-1}$ and $n=1.89$ [Carsel, 1988]). The hydrological model was run at a time step of 0.1 day for reasons of stability and the coupling between the vegetation and hydrological model was on a daily basis.

[46] In the vegetation model two plant functional types are defined. The first type is better adapted to wet conditions, in which it experiences less oxygen stress than the second type, 

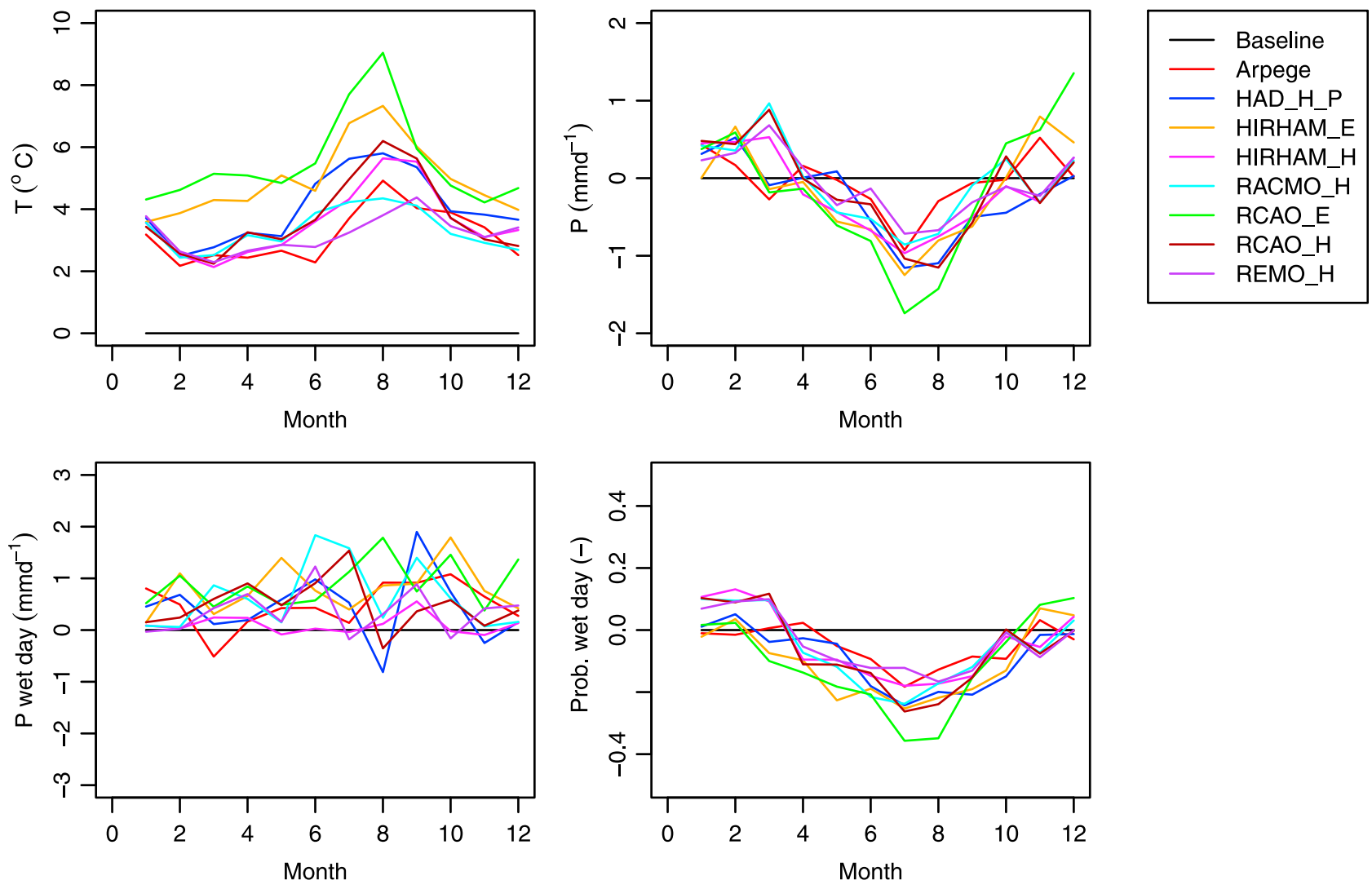

Figure 2. Outcomes of the PRUDENCE GCM-RCM combinations for the future time period (20712100) for Eindhoven, Netherlands, relative to the baseline period (1961-1990): (top left) change in temperature, (top right) change in daily precipitation amount,(bottom left) change in precipitation on days that it rains, and (bottom right) change in probability that it rains on a single day. $\mathrm{P}$, amount of precipitation; $\mathrm{P}$ wet day, the amount of precipitation on days with precipitation; Prob. wet day, probability of a day with precipitation $(P>0 \mathrm{~mm})$.

whereas the second type is better adapted to dry conditions, in which it experiences less water stress than the first type. The parameters that differ between the two species are listed in Table 1.

[47] For every GCM-RCM combination a 1000 year stochastic weather series was produced. The first 400 years were used for spin-up of the ecohydrological model and the following 600 years were used as results. These results were analyzed by looking at the biomass distribution along the hillslope, average soil moisture content, average groundwater level, average evapotranspiration and the difference between precipitation and evapotranspiration as measure of average groundwater recharge. We simulated changesin $\mathrm{P}, \mathrm{T}$ and $\mathrm{CO}_{2}$ separately as well as full climate change, by changing the factors simultaneously. This way we were able to analyze the separate contributions to the combined effect of climate change.

\section{Results}

[48] In this section first the outcomes of the baseline run are described. Then the separate influence of temperature rise, change in precipitation pattern and rise in atmospheric $\mathrm{CO}_{2}$ concentration on the ecohydrological system are explained and finally, we describe the effect of expected climate change, by changing all variables simultaneously.
[49] The results of the baseline run are plotted repeatedly in Figures 3, 4, 5, and 6, showing the main variables influencing the water balance and the effect on biomass for the different scenarios. The results are presented as average values of a 600 yearperiod and 100 cells parallel to the slope. In this period a quasi steady state exists in the ecohydrological system, but spatial and temporal dynamics exist. These are for large part driven by variations in meteorological input. For more information about within year temporal variation we refer to Brolsma et al. [2010a]. For reference we also provided dynamic content showing an animation of the 600 years simulation for the baseline run. ${ }^{1}$

[50] The highest biomass $\left(22 \mathrm{~kg} \mathrm{~m}^{-2}\right)$ is reached by the wet-adapted species near the base of the slope. At the base of the slope biomass is slightly lower as a result of oxygen stress. Moving further upslope the biomass of the wet-adapted species decreases, while the biomass of the dry-adapted species increases. This transition zone is located between 60 and $130 \mathrm{~m}$. Upslope of $130 \mathrm{~m}$ the dry-adapted species dominates with the highest biomass just upslope of $130 \mathrm{~m}$ and a fairly constant biomass of $5 \mathrm{~kg} \mathrm{~m}^{-2}$ along the rest of the slope. Evapotranspiration is also highest downslope and lowest upslope and is almost constant except for the transition zone $(60-200 \mathrm{~m})$ in between. This transition zone

\footnotetext{
${ }^{1}$ Animation 1 is available in the HTML.
} 

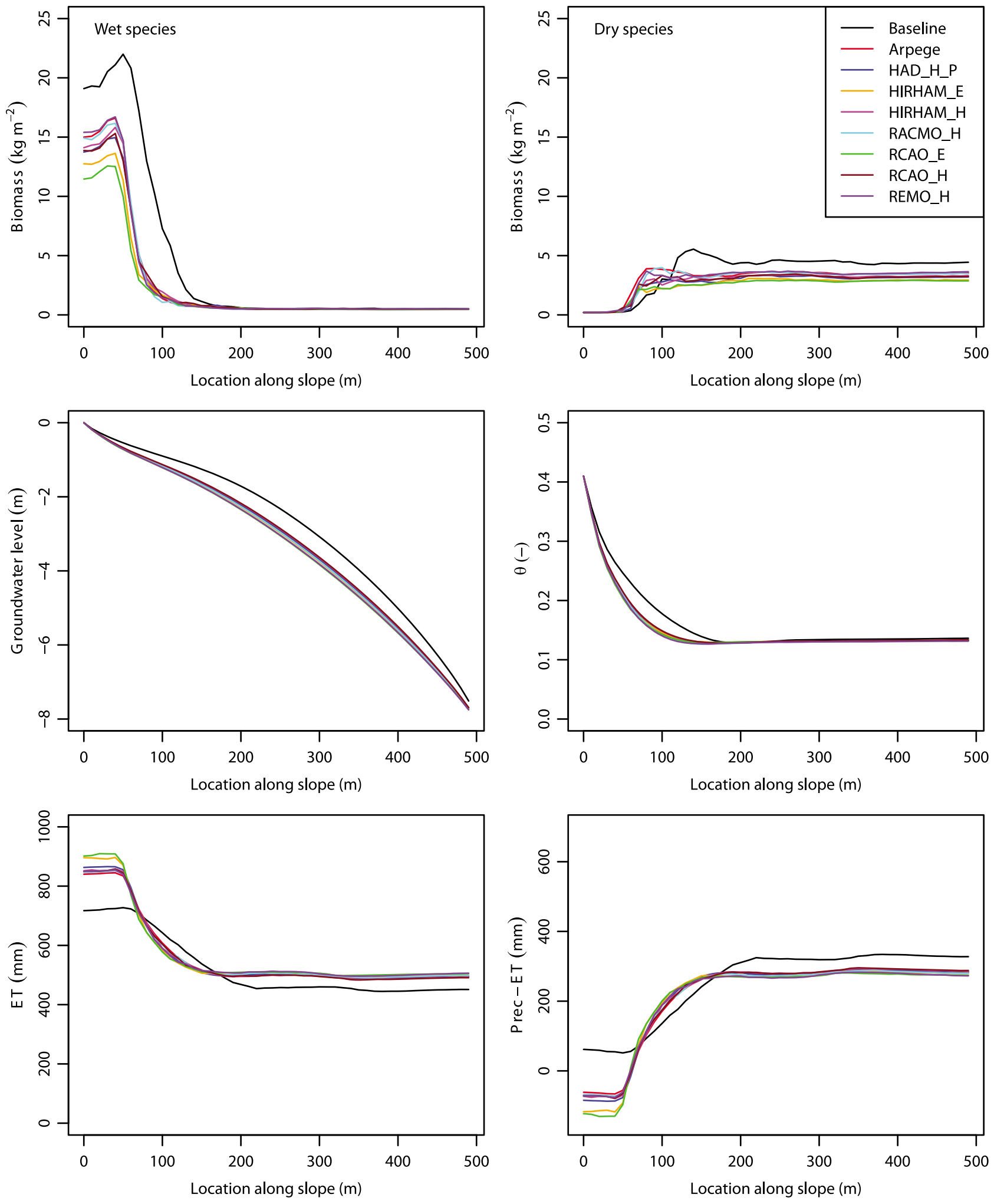

Figure 3. The effect of change in temperature on a groundwater-controlled forest ecosystem on a slope. Plots show the effect on biomass of the wet-adapted and the drought-adapted species, groundwater level relative to the surface, root zone soil moisture content, evapotranspiration, and (sub)surface runoff. The lines represent average values of 600 years and 100 cells parallel to the slope. The base of the slope is located at $0 \mathrm{~m}$. 

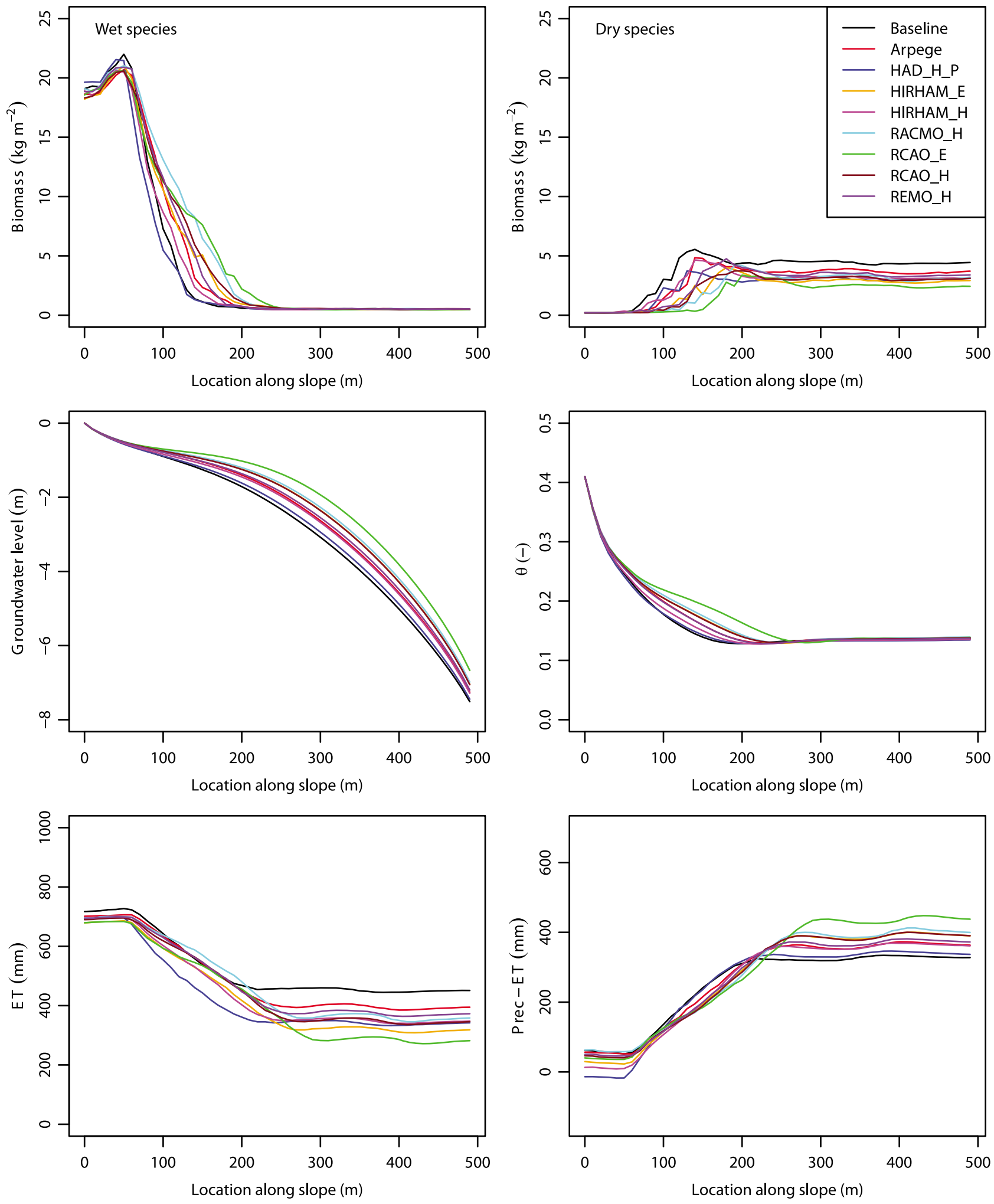

Figure 4. The effect of change in precipitation on a groundwater-controlled forest ecosystem on a slope. Plots show the effect on biomass of the wet-adapted and the drought-adapted species, groundwater level relative to the surface, root zone soil moisture content, evapotranspiration, and (sub)surface runoff. The lines represent average values of 600 years and 100 cells parallel to the slope. The base of the slope is located at $0 \mathrm{~m}$. 

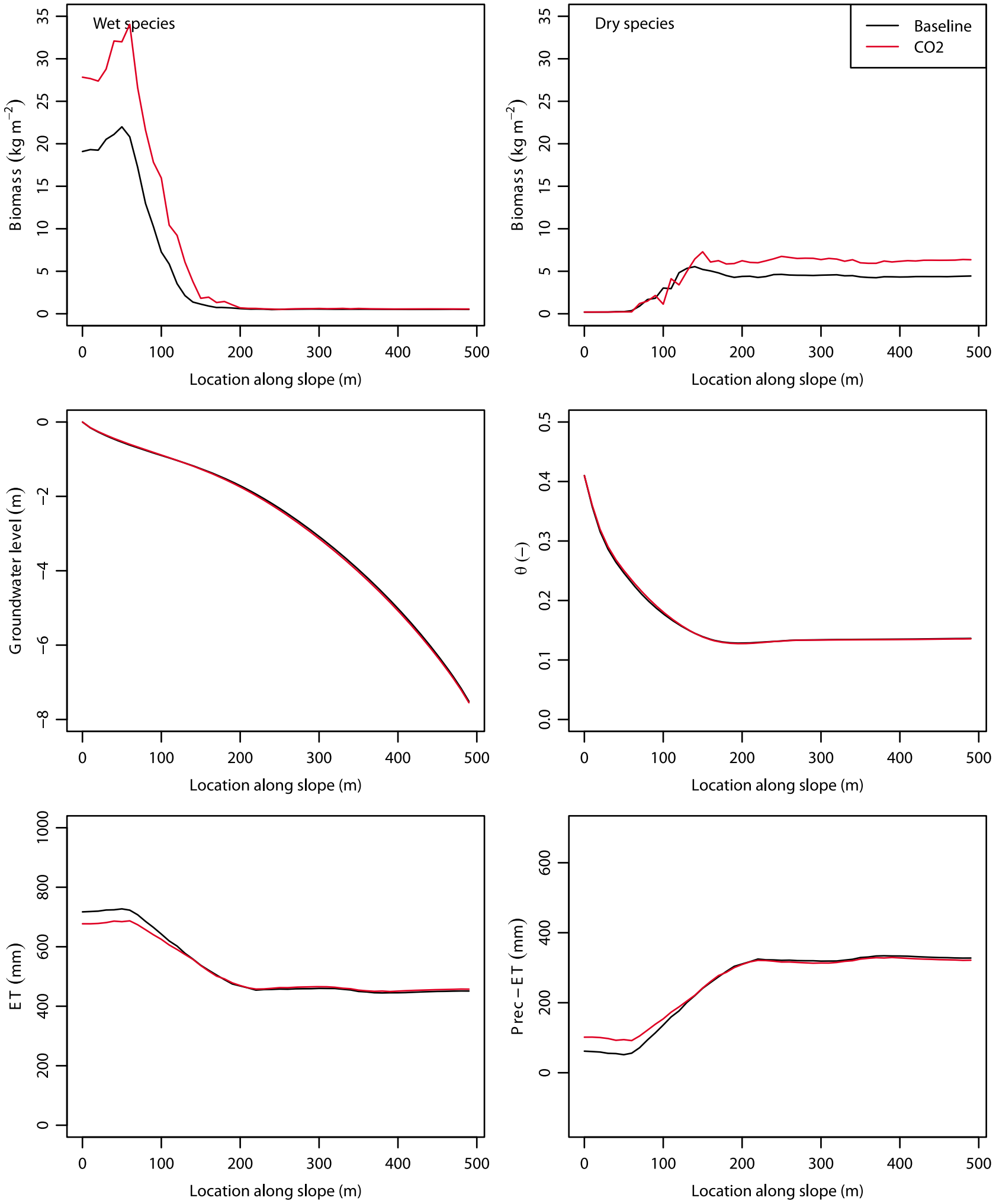

Figure 5. The effect of change in atmospheric $\mathrm{CO}_{2}$ concentration on a groundwater-controlled forest ecosystem on a slope. Plots show the effect on biomass of the wet-adapted and the drought-adapted species, groundwater level relative to the surface, root zone soil moisture content, evapotranspiration, and (sub)surface runoff. The lines represent average values of 600 years and 100 cells parallel to the slope. The base of the slope is located at $0 \mathrm{~m}$. 

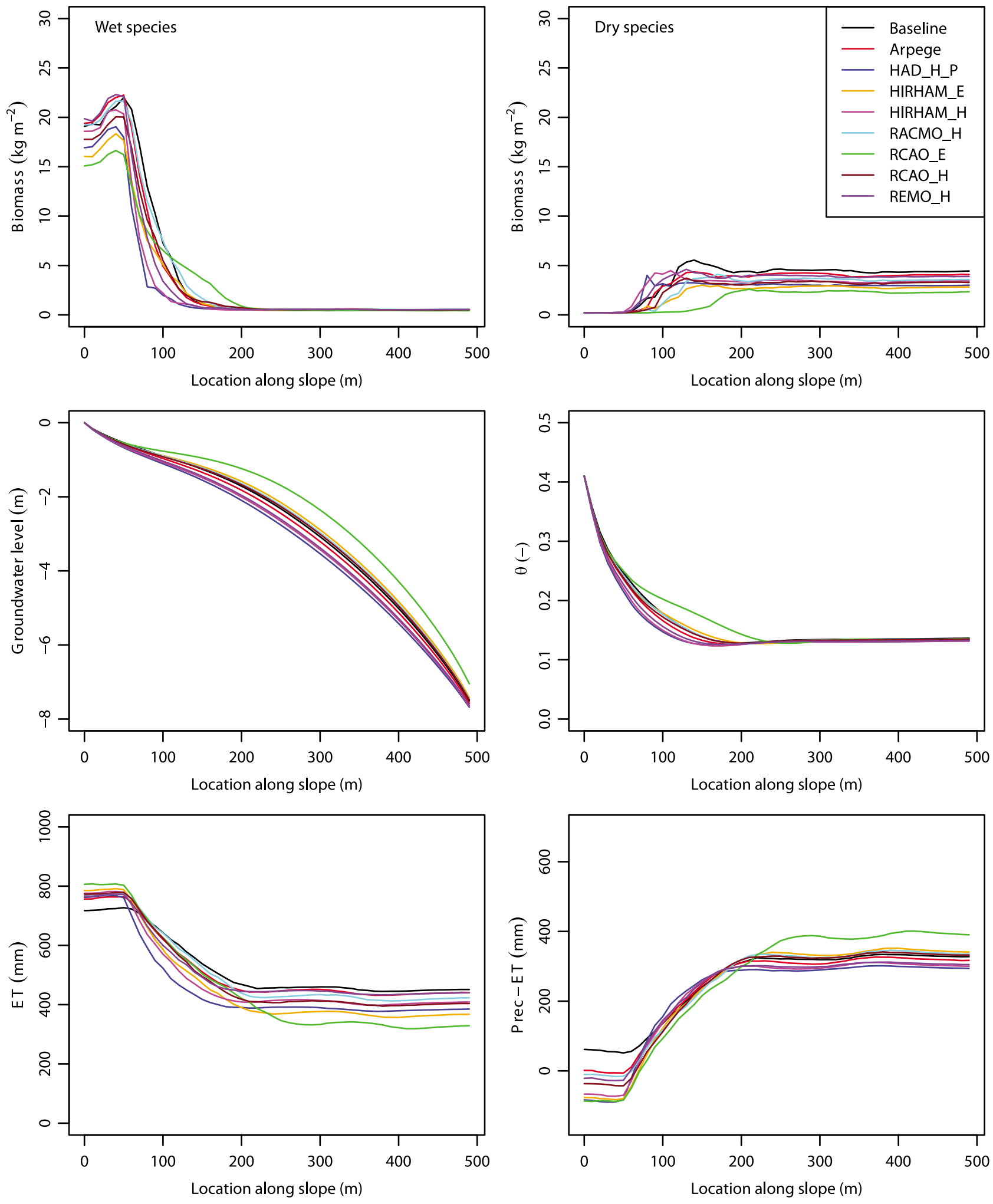

Figure 6. Combined effect of change in $\mathrm{CO}_{2}$, temperature, and precipitation on a groundwatercontrolled forest ecosystem on a slope. Plots show the effect on biomass of the wet-adapted and the drought-adapted species, groundwater level relative to the surface, root zone soil moisture content, evapotranspiration, and (sub)surface runoff. The lines represent average values of 600 years and 100 cells parallel to the slope. The base of the slope is located at $0 \mathrm{~m}$. 
Table 3. Averages of Biomass and Water Balance Components in the Different Climate Scenarios ${ }^{\mathrm{a}}$

\begin{tabular}{|c|c|c|c|c|c|c|c|c|c|c|c|}
\hline & $P$ & $B_{\text {wet }}$ & $B_{d r y}$ & $B_{t o t}$ & $E_{\text {wet }}$ & $E_{d r y}$ & $E_{\text {tot }}$ & $T r_{\text {wet }}$ & $T r_{d r y}$ & $T r_{t o t}$ & $P-E T$ \\
\hline \multicolumn{12}{|c|}{ Temperature } \\
\hline Baseline & 778.8 & 4.5 & 3.7 & 8.1 & 56.1 & 94.6 & 150.7 & 157.6 & 216.5 & 374.1 & 254.0 \\
\hline Arpege & 778.8 & 2.7 & 3.1 & 5.8 & 56.1 & 112.8 & 169.6 & 143.5 & 248.0 & 391.5 & 217.7 \\
\hline HAD-H-P & 778.8 & 2.5 & 2.7 & 5.2 & 56.1 & 107.3 & 167.5 & 155.9 & 238.6 & 394.5 & 216.8 \\
\hline HIRHAM-E & 778.8 & 2.3 & 2.5 & 4.8 & 56.1 & 106.1 & 167.0 & 159.6 & 239.7 & 399.4 & 212.5 \\
\hline HIRHAM-H & 778.8 & 2.6 & 2.8 & 5.4 & 56.1 & 107.7 & 167.3 & 153.6 & 239.1 & 392.7 & 218.8 \\
\hline RACMO-H & 778.8 & 2.7 & 3.0 & 5.7 & 56.1 & 113.5 & 171.2 & 145.0 & 246.9 & 391.9 & 215.7 \\
\hline RCAO-E & 778.8 & 2.1 & 2.4 & 4.5 & 56.1 & 108.9 & 169.3 & 156.1 & 245.0 & 401.0 & 208.5 \\
\hline RCAO-H & 778.8 & 2.6 & 2.8 & 5.3 & 56.1 & 107.3 & 166.1 & 153.1 & 240.1 & 393.1 & 219.5 \\
\hline REMO-H & 778.8 & 2.7 & 3.0 & 5.7 & 56.1 & 115.8 & 175.1 & 145.2 & 245.5 & 390.7 & 213.0 \\
\hline \multicolumn{12}{|c|}{ Precipitation } \\
\hline Baseline & 778.8 & 4.5 & 3.7 & 8.1 & 56.1 & 94.6 & 150.7 & 157.6 & 216.5 & 374.1 & 254.0 \\
\hline Arpege & 757.9 & 4.9 & 3.0 & 7.8 & 51.8 & 69.5 & 121.3 & 182.4 & 185.5 & 367.9 & 268.7 \\
\hline HAD-H-P & 679.0 & 4.2 & 2.5 & 6.7 & 38.5 & 54.7 & 93.3 & 163.5 & 173.2 & 336.7 & 249.0 \\
\hline HIRHAM-E & 708.6 & 4.9 & 2.2 & 7.2 & 40.7 & 45.1 & 85.8 & 196.1 & 153.2 & 349.3 & 273.5 \\
\hline HIRHAM-H & 709.2 & 4.5 & 2.7 & 7.1 & 44.1 & 60.7 & 104.8 & 171.8 & 174.8 & 346.6 & 257.8 \\
\hline RACMO-H & 758.1 & 5.6 & 2.3 & 8.0 & 50.7 & 52.1 & 102.8 & 215.9 & 157.7 & 373.6 & 281.7 \\
\hline RCAO-E & 719.6 & 5.5 & 1.8 & 7.3 & 41.3 & 36.0 & 77.3 & 222.7 & 126.4 & 349.1 & 293.2 \\
\hline RCAO-H & 736.2 & 5.2 & 2.4 & 7.5 & 47.8 & 52.1 & 99.9 & 203.2 & 157.4 & 360.7 & 275.6 \\
\hline REMO-H & 745.1 & 5.0 & 2.7 & 7.7 & 49.0 & 61.0 & 110.0 & 190.7 & 175.3 & 366.0 & 269.1 \\
\hline \multicolumn{12}{|c|}{$\mathrm{CO}_{2}$} \\
\hline Baseline & 778.8 & 4.5 & 3.7 & 8.1 & 56.1 & 94.6 & 150.7 & 157.6 & 216.5 & 374.1 & 254.0 \\
\hline Baseline and $\mathrm{CO} 2$ & 778.8 & 6.9 & 4.9 & 11.9 & 61.5 & 100.3 & 161.8 & 155.7 & 201.8 & 357.5 & 259.5 \\
\hline \multicolumn{12}{|c|}{ Total } \\
\hline Baseline & 778.8 & 4.5 & 3.7 & 8.1 & 56.1 & 94.6 & 150.7 & 157.6 & 216.5 & 374.1 & 254.0 \\
\hline Arpege & 757.9 & 4.2 & 3.3 & 7.5 & 57.3 & 95.2 & 152.5 & 157.8 & 207.0 & 364.8 & 240.7 \\
\hline HAD-H-P & 679.0 & 3.1 & 2.6 & 5.7 & 45.0 & 77.5 & 122.5 & 141.0 & 196.4 & 337.4 & 219.1 \\
\hline HIRHAM-E & 708.6 & 3.5 & 2.2 & 5.7 & 48.4 & 66.3 & 114.7 & 175.4 & 177.9 & 353.2 & 240.7 \\
\hline HIRHAM-H & 709.2 & 3.4 & 3.0 & 6.4 & 50.6 & 93.9 & 144.5 & 138.2 & 203.4 & 341.6 & 223.1 \\
\hline RACMO-H & 758.1 & 4.4 & 2.8 & 7.3 & 59.9 & 84.1 & 143.9 & 177.6 & 190.4 & 368.0 & 246.1 \\
\hline RCAO-E & 719.6 & 3.7 & 1.6 & 5.4 & 55.5 & 52.9 & 108.4 & 215.5 & 138.9 & 354.4 & 256.8 \\
\hline RCAO-H & 736.2 & 3.9 & 2.6 & 6.6 & 56.6 & 81.6 & 138.2 & 170.5 & 186.5 & 357.0 & 240.9 \\
\hline REMO-H & 745.1 & 3.9 & 3.3 & 7.2 & 55.1 & 97.8 & 152.9 & 148.3 & 212.4 & 360.6 & 231.6 \\
\hline
\end{tabular}

${ }^{\mathrm{a}}$ Effects of temperature rise, change in precipitation pattern, $\mathrm{CO}_{2}$ concentration, and effect of simultaneous change on the following variables: biomass wet vegetation $\left(B_{\text {wet }}\right)$, dry vegetation $\left(B_{d r y}\right)$, total vegetation $\left(B_{t o t}\right)$, evaporation wet vegetation $\left(E_{\text {wet }}\right)$, evaporation dry vegetation $\left(E_{d r y}\right)$, evaporation total vegetation $\left(E_{t o t}\right)$, transpiration wet vegetation $\left(T r_{\text {wet }}\right)$, transpiration dry vegetation $\left(T r_{d r y}\right)$, transpiration total vegetation $\left(T r_{t o t}\right)$, and net precipitation $(P-E T)$. Biomass is given in $\mathrm{kg} \mathrm{m}^{-2}$, and fluxes are given in $\mathrm{mm} \mathrm{yr}^{-1}$.

is wider than the transition zone of the vegetation. This indicates that ET in this zone is not only driven by biomass and vegetation type, but also by the proximity of groundwater and therefore capillary rise or reduced groundwater recharge. Average groundwater and root zone soil moisture content (0.41-0.12) show a gradient from high to low moving in upslope direction. Because of the assumption of now flow boundaries the groundwater table downslope is at the surface and almost constant.

\subsection{Temperature Change}

[51] The effect of temperature change on the ecohydrological system is shown in Figure 3 and Table 3 . In all model runs the biomass of both species decreases and the transition zone between species moves downslope. Because of the shift of the transition zone the biomass of the dry species increases in this zone, but total biomass decreases. This coincides with an increase in ET along most part of the slope except for the zone where the shift occurs (80 to $190 \mathrm{~m})$. Because the precipitation amount is equal in all model runs, groundwater recharge shows the opposite pattern of ET. As a result, the groundwater level drops as well as the root zone soil moisture content. The decrease in soil moisture content is most pronounced in the transition zone, which is caused by the disconnection between groundwater level and the root zone during a longer period of the year and the shift downward of the drought-adapted species that is capable of extracting more water from the soil.

[52] Biomass decreases, because respiration increases faster with an increase in temperature than carbon assimilation in the temperature range between the current climate and the future scenarios. The increase in ET is mostly caused by the increase in vapor pressure deficit $(D)$ and the slope of the vapor pressure curve, $(\Delta)$. Both RCM runs based on the ECHAM4/OPYC GCM (HIRHAM-E, RCAO-E) show a stronger temperature increase than the RCM runs based on the HadAM3 GCM (HIRHAM-H, RCAO-H) and therefore have stronger effect on vegetation and hydrology.

\subsection{Precipitation Change}

[53] The effect of precipitation on the ecohydrological system is shown in Figure 4 and Table 3. The maximum biomass of the wet-adapted vegetation remains approximately the same $\left(20 \mathrm{~kg} \mathrm{~m}^{-2}\right)$, but the zone where it dominates becomes wider and the overall biomass of wet species increases. However, the maximum biomass as well as the width of the zone of the drought-adapted species decreases. Evapotranspiration decreases almost everywhere, although upslope much more (50-200 $\mathrm{mm}$ ) than downslope (20$30 \mathrm{~mm}$ ). Therefore, the groundwater recharge (that is based 
on both precipitation and ET) upslope increases whereas downslope it decreases. The groundwater level rises as well as the soil moisture content. The reduction in soil moisture content is especially prominent in the intermediate zone.

[54] The decrease in biomass of the dry species is caused by the decrease in annual precipitation, and especially in summer precipitation when atmospheric demand is highest. This causes more water stress for vegetation, higher leaf temperatures due to less ET and more respiration, while because of closure of the stomata the carbon assimilation decreases. Interception evaporation drops in summer because of the decreased precipitation and slightly lower $L A I$. At the same time the amount of precipitation on days that it rains, i.e., the intensity, increases. This results in more through fall because the interception capacity of the canopy is more frequently exceeded, which is reinforced by decreased $L A I$ (biomass). Additionally in winter, when interception evaporation is negligible, precipitation increases. This causes an increase in the annual sum of groundwater recharge and therefore higher groundwater levels and higher average soil moisture contents, especially midslope. This eventually gives room for upslope extension of the zone of wet-adapted species.

\subsection{Change in Atmospheric Carbon Dioxide}

[55] The increase of atmospheric $\mathrm{CO}_{2}$ content has two opposite effects on evapotranspiration. First, the increasing gradient between atmospheric and intercellular $\mathrm{CO}_{2}$ causes a larger $\mathrm{CO}_{2}$ flux into the leaf, resulting in higher assimilation rates and thus a higher biomass. This can be seen throughout the hillslope in Figure 5 for both dry and wet-adapted vegetation. A higher biomass increases evapotranspiration because of an increased transpiration area (LAI) and increased interception evaporation. Second, a higher atmospheric $\mathrm{CO}_{2}$ content results in a reduction of maximum stomatal conductance $\left(7.4 \mathrm{~mm} \mathrm{~d}^{-1}\right.$ instead of $\left.10 \mathrm{~mm} \mathrm{~d}^{-1}\right)$ and thus a reduced transpiration per unit leaf area [Kruijt et al., 2008]. Figure 5 shows that the net effect downslope is a decrease in evaporation. Apparently vegetation growth, i.e., the increase in biomass, is light limited so that it cannot offset the decrease in transpiration due to $\mathrm{CO}_{2}$ reduced stomatal conductance. Upslope however both effects seem to cancel out. Here, the vegetation growth and evaporation during the summer is water limited. Because of stomatal closure less water is transpired, which leaves additional water to remain in the soil. This additional water is however immediately used up by the increased biomass which, mainly because of increased interception evaporation, completely compensates the decreased transpiration by reduced stomatal conductance. As can be seen, the effect of $\mathrm{CO}_{2}$ rise on groundwater level and soil moisture is small, because precipitation is constant and evaporation almost remains the same.

\subsection{Combined Effect}

[56] The combined effect of temperature, precipitation and $\mathrm{CO}_{2}$ change can be seen in Figure 6 and Table 3. Biomass will decrease both downslope and upslope for both species. Because the influence of precipitation downslope is negligible, the effect of change in temperature is dominant, leading to decreased biomass due to increased respiration. Upslope the dominant factor cannot be recognized as both temperature rise and precipitation change result in a decrease in biomass. Their effect is slightly counterbalanced by the increase in atmospheric $\mathrm{CO}_{2}$ concentration. Downslope ET increases while annual precipitation decreases more, resulting in an evapotranspiration surplus.

[57] Downslope, where vegetation growth is not water limited, the increase in temperature is the main cause for the decrease in biomass due to increased respiration. Upslope, the increase in temperature, the decrease in annual precipitation and increased difference between summer and winter precipitation, cause high water stress and therefore a net reduction in transpiration and carbon assimilation and an increase in respiration, resulting in a lower biomass and $L A I$. For the RCM runs based on the ECHAM4/OPYC GCM, the decrease in biomass is so large that it results in an increase in groundwater recharge upslope and therefore a rise in ground water level and an increase in root zone soil moisture content. Surprisingly, the scenarios based on the HadAM3 model show the opposite effect: A smaller increase in temperature and difference between winter and summer precipitation result in a smaller decrease in biomass. Combined with a smaller increase in winter precipitation the net effect is a decrease in groundwater recharge, resulting in a drop in groundwater level and a decrease in soil moisture content.

\section{Discussion and Conclusions}

[58] Figure 7 summarizes the results from the sensitivity analysis showing the effects of climate change and individual change in temperature, precipitation and atmospheric $\mathrm{CO}_{2}$ on the ecohydrological variables. We separated the effects downslope and upslope, distinguishing between the zone that is never water limited from the zone that can become water limited in the warm/dry season as well as the RCM runs based on the ECHAM4/OPYC and HadAM3 GCM.

[59] As to be expected, given the lower no-flow boundary condition for groundwater, precipitation change has hardly any effect on downslope groundwater and root zone soil moisture conditions. As a result, the effect of precipitation on biomass downslope is negligible. Upslope where groundwater levels are deeper, the soil moisture content is lower and the effect of the change in precipitation regime is much larger as vegetation growth is already limited by water availability. Because root zone soil moisture content downslope is high and hardly changes because of the shallow groundwater table, the effect of $\mathrm{CO}_{2}$ rise on biomass downslope is large. Upslope the effect is much smaller as water is the limiting factor in vegetation growth. The effect of temperature rise is similar, because the increase in both respiration and carbon assimilation is similar. As a result of a simultaneous change in precipitation, temperature and atmospheric $\mathrm{CO}_{2}$ concentration, biomass both upslope and downslope decreases, indicating the dominance of the temperature (mostly downslope) and precipitation effect (mostly upslope). Surprisingly the RCM runs based on the ECHAM4/OPYC GCM, show an increase in groundwater level and soil moisture content, while the RCM runs based on HadAM3 show a decrease in both variables. This shows that sign of the response can be dependent on the magnitude of the climate change signal and is thus very nonlinear in this system.

[60] The results in Figure 7 also show that the effect of climate change on hydrological variables can be highly nonlinear, such that even the sign of change can be different 
- large decrease $\bullet$ medium decrease $\bullet$ no change $\bullet$ medium increase $\bullet$ large increase

\begin{tabular}{|c|c|c|c|c|c|c|c|c|c|c|c|c|c|}
\hline \multirow[t]{2}{*}{ Change } & \multirow[t]{2}{*}{ Model } & \multicolumn{6}{|c|}{ Downslope } & \multicolumn{6}{|c|}{ Upslope } \\
\hline & & $B_{w e t}$ & $A_{\text {wet }}$ & $\mathrm{E}$ & $\mathrm{P}-\mathrm{E}$ & G & $\theta$ & $B_{d r y}$ & $A_{d r y}$ & $\mathrm{E}$ & $\mathrm{P}-\mathrm{E}$ & G & $\theta$ \\
\hline \multirow[t]{2}{*}{ Temperature } & HadAM3 & $\bullet$ & - & $\bullet$ & $\bullet$ & $\bullet$ & $\bullet$ & $\bullet$ & - & - & - & - & $\bullet$ \\
\hline & ECHAM4/OPYC & $\bullet$ & - & • & $\bullet$ & $\bullet$ & • & • & $\bullet$ & - & $\bullet$ & - & $\bullet$ \\
\hline \multirow[t]{2}{*}{ Precipitation } & HadAM3 & - & - & - & - & - & • & - & - & $\bullet$ & - & - & $\bullet$ \\
\hline & ECHAM4/OPYC & - & - & - & - & $\bullet$ & $\bullet$ & - & $\bullet$ & - & - & - & $\bullet$ \\
\hline $\mathrm{CO}_{2}$ & & $\bullet$ & - & - & - & - & - & - & $\bullet$ & - & - & $\bullet$ & - \\
\hline \multirow[t]{2}{*}{ Combined } & HadAM3 & $\bullet$ & - & - & $\bullet$ & $\bullet$ & - & $\bullet$ & $\bullet$ & $\bullet$ & $\bullet$ & $\bullet$ & $\bullet$ \\
\hline & ECHAM4/OPYC & $\bullet$ & • & $\bullet$ & $\bullet$ & • & • & $\bullet$ & • & $\bullet$ & • & • & $\bullet$ \\
\hline
\end{tabular}

Figure 7. Summary of the outcomes of the different scenarios (2071-2100) compared to the baseline run (1961-1990). Downslope refers to the lower $50 \mathrm{~m}$ of the slope and upslope to the upper $50 \mathrm{~m}$ of the slope, except for the areas $\left(A_{w e t}\right.$ and $\left.A_{d r y}\right)$ which correspond to the entire slope. The results are shown separately for the RCM runs based on the HadAM3 and the ECHAM4/OPYC GCM. $B_{\text {wet }}$, biomass wet-adapted species; $B_{d r y}$, biomass dry-adapted species; $A_{w e t}$, area wet-adapted species; $A_{d r y}$, area dry-adapted species; E, evapotranspiration; $P-E$, precipitation minus evapotranspiration; G, groundwater level; $\theta$, soil moisture content. Five classes of change are used: red, large decrease; orange, medium decrease; gray, no change; light green, medium increase; dark green, large increase.

depending on the magnitude of change in temperature and precipitation over the year. Clearly, the combined effect of the three factors temperature, precipitation and $\mathrm{CO}_{2}$ on the ecohydrological system is far form straightforward. It depends on the position in the landscape and cannot be simply deduced from the individual effects.

[61] The results also shows the clear presence of spatial interaction. The upslope-downslope interaction, which is most pronounced as a result of change in precipitation regime, where although yearly rainfall decreases, rainfall in winter increases. Decreased upslope biomass and increased rainfall in winter cause the groundwater recharge to increase upslope as a result of increased through fall in winter. The resulting rise in groundwater level causes wetter conditions downslope and therefore an enlargement of the zone where wet-adapted vegetation occurs. This could not have been predicted using a model that does not include lateral groundwater flow. In particular, the nonlinear response to magnitude and the upslope-downslope effects, show that predicting the effect of climate change on this temperate ecosystem can be far from straightforward and calls for models that fully couple biophysical vegetation models with the hydrological system. That is, we need ecohydrological models that are robust under climate change.

[62] We stress that the results show the response of one particular system and one $\mathrm{CO}_{2}$ emission scenario, although existing of an ensemble of eight projections. Therefore this study cannot be used to draw general conclusions about the effect of climate change in absolute sense. It mostly serves as an example to show the complexity of the response of the system and give directions for future research. Moreover, the validation of the model or comparison of the model as a whole against field data is rather impractical. Experiments with scaled but real vegetation on artificial hillslopes [Hopp et al., 2009; Kleinhans et al., 2010] may be a way to test whether nonlinear effects observed in the simulations are a property of the model or of the real system.

[63] Acknowledgments. We would like to thank Stephen Blenkinsop, Aidan Burton, and Hayley Fowler of Newcastle University for providing the calculated change factors of precipitation and temperature statistics of the selected RCM experiments and for their assistance with the RainSim V3 rainfall model. Data have been provided through the PRUDENCE data archive, funded by the EU through contract EVK2-CT2001-00132. This work was sponsored by the Stichting Nationale Computerfaciliteiten (National Computing Facilities Foundation (NCF)) for the use of supercomputer facilities, with financial support from the Nederlandse Organisatie voor Wetenschappelijk Onderzoek (Netherlands Organization for Scientific Research (NWO)). We also thank three anonymous reviewers for their constructive comments that helped to improve this paper.

\section{References}

Allen, R., L. Pereira, D. Raes, and M. Smith (1998), Crop evapotranspiration, Guidelines for computing crop water requirements, Tech. Rep., 56, Food and Agric. Organ., Rome.

Arora, V. K., and G. J. Boer (2006), Simulating competition and coexistence between plant functional types in a dynamic vegetation model, Earth Interact., 10, 1-30.

Band, L. E., P. Patterson, R. Nemani, and S. W. Running (1993), Forest ecosystem processes at the watershed scale-Incorporating hillslope hydrology, Agric. For. Meteorol., 63(1-2), 93-126.

Bartholomeus, R. P., J. P. M. Witte, P. M. van Bodegom, J. C. van Dam, and R. Aerts (2008), Critical soil conditions for oxygen stress to plant roots: Substituting the Feddes-function by a process-based model, J. Hydrol., 360(1-4), 147-165.

Brolsma, R. J., and M. F. P. Bierkens (2007), Groundwater-soil watervegetation dynamics in a temperate forest ecosystem along a slope, Water Resour. Res., 43, W01414, doi:10.1029/2005WR004696.

Brolsma, R. J., L. P. H. van Beek, and M. F. P. Bierkens (2010a), Vegetation competition model for water and light limitation. II: Spatial dynamics of groundwater and vegetation, Ecol. Modell., 221(10), 1364-1377. 
Brolsma, R. J., D. Karssenberg, and M. F. P. Bierkens (2010b), Vegetation competition model for water and light limitation. I: Model description, one-dimensional competition and the influence of groundwater, Ecol. Modell., 221(10), 1348-1363.

Burton, A., C. G. Kilsby, H. J. Fowler, P. S. P. Cowpertwait, and P. E. O'Connell (2008), Rainsim: A spatial-temporal stochastic rainfall modelling system, Environ. Modell. Software, 23(12), 1356-1369.

Carsel, R. (1988), Developing joint probability distributions of soil water retention characteristics, Water Resour. Res., 5(5), 755-769.

Christensen, J. H., T. R. Carter, M. Rummukainen, and G. Amanatidis (2007), Evaluating the performance and utility of regional climate models: The PRUDENCE project, Clim. Change, 81, 1-6.

Cowpertwait, P. S. P. (1995), A generalized spatial-temporal model of rainfall based on a clustered point process, Proc. R. Soc. London, Ser. A, 450(1938), 163-175.

Daly, E., A. Porporato, and I. Rodriguez-Iturbe (2004), Coupled dynamics of photosynthesis, transpiration, and soil water balance. Part I: Upscaling from hourly to daily level, J. Hydrometeorol., 5(3), 546-558.

Daly, E., Y. Zinger, A. Deletic, and T. D. Fletcher (2009), A possible mechanism for soil moisture bimodality in humid-land environments, Geophys. Res. Lett., 36, L07402, doi:10.1029/2008GL036933.

Eagleson, P. S. (1978), Climate, soil, and vegetation: 1. Introduction to water balance dynamics, Water Resour. Res., 14(5), 705-712.

Farquhar, G. D., S. Von Caemmerer, and J. A. Berry (1980), A biochemical model of photosynthetic $\mathrm{CO}_{2}$ assimilation in leaves of $\mathrm{C} 3$ species, Planta, 149, 78-90.

Feddes, R. A., P. Kowalik, and H. Jaradny (1978), Simulation of Field Water Use and Crop Yield, 189 pp., Pudoc Sci., Wageningen, Netherlands.

Fowler, H. J., S. Blenkinsop, and C. Tebaldi (2007), Linking climate change modelling to impacts studies: Recent advances in downscaling techniques for hydrological modelling, Int. J. Climatol., 27(12), 1547-1578.

Friend, A. D., A. K. Stevens, R. G. Knox, and M. G. R. Cannell (1997), A process-based, terrestrial biosphere model of ecosystem dynamics (Hybrid v3.0), Ecol. Modell., 95(2-3), 249-287.

Hopp, L., C. Harman, S. L. E. Desilets, C. B. Graham, J. J. McDonnell, and P. A. Troch (2009), Hillslope hydrology under glass: Confronting fundamental questions of soil-water-biota co-evolution at biosphere 2, Hydrol. Earth Syst. Sci., 13(11), 2105-2118.

Jarvis, P. G. (1976), The interpretation of the variations in leaf water potential and stomatal conductance found in canopies in the field, Philos. Trans. R. Soc. London, 273, 593-610.

Karnosky, D. F. (2003), Impacts of elevated atmospheric $\mathrm{CO}_{2}$ on forest trees and forest ecosystems: Knowledge gaps, Environ. Int., 29(2-3), $161-169$.

Kilsby, C. G., P. D. Jones, A. Burton, A. C. Ford, H. J. Fowler, C. Harpham, P. James, A. Smith, and R. L. Wilby (2007), A daily weather generator for use in climate change studies, Environ. Modell. Software, 22(12), 1705-1719.

Kleinhans, M. G., M. F. P. Bierkens, and M. Van der Perk (2010), Hydrologists, bring out shovels and garden hoses and hit the dirt, Hydrol. Earth Sys. Sci. Discuss., 14, 369-382.
Kruijt, B., J.-P. M. Witte, C. M. J. Jacobs, and T. Kroon (2008), Effects of rising atmospheric $\mathrm{CO}_{2}$ on evapotranspiration and soil moisture: A practical approach for the Netherlands, J. Hydrol., 349(3-4), 257-267.

Medlyn, B. E., et al. (2001), Stomatal conductance of forest species after long-term exposure to elevated $\mathrm{CO}_{2}$ concentration: A synthesis, New Phytol., 149(2), 247-264.

Monteith, J. L. (1965), Evaporation and environment, Symp. Soc. Exp. Biol., 19, 205-234.

Nakicenovic, N., and R. Swart (Eds.) (2000), IPCC Special Report on Emission 437 Scenarios, 438 ed., Cambridge Univ. Press, Cambridge, U. K.

Prentice, I. C., M. T. Sykes, and W. Cramer (1993), A simulation model for the transient effects of climate change on forest landscapes, Ecol. Modell., 65(1-2), 51-70.

Richardson, C. (1981), Stochastic simulation of daily precipitation, temperature, and solar radiation, Water Resour. Res., 17(1), 182-190.

Rodriguez-Iturbe, I. (2000), Ecohydrology: A hydrologic perspective of climate-soil-vegetation dynamics, Water Resour. Res., 36(1), 3-9.

Rodriguez-Iturbe, I., and A. Porporato (2004), Ecohydrology of WaterControlled Ecosystems, Cambridge Univ. Press, Cambridge, U. K.

Rodriguez-Iturbe, I., P. D’Odorico, F. Laio, L. Ridolfi, and S. Tamea (2007), Challenges in humid land ecohydrology: Interactions of water table and unsaturated zone with climate, soil, and vegetation, Water Resour. Res., 43, W09301, doi:10.1029/2007WR006073.

Saxe, H., M. G. R. Cannell, B. Johnsen, M. G. Ryan, and G. Vourlitis (2001), Tree and forest functioning in response to global warming, New Phytol., 149(3), 369-399.

Shuttleworth, W. (1993), Evaporation, in Handbook of Hydrology, edited by D. Maidment, pp. 4.1-4.53, McGraw-Hill, New York.

Sitch, S., et al. (2003), Evaluation of ecosystem dynamics, plant geography and terrestrial carbon cycling in the LPJ dynamic global vegetation model, Global Change Biol., 9(2), 161-185.

Solomon, S., D. Qin, M. Manning, Z. Chen, M. Marquis, K. Averyt, M. Tignor, and H. Miller (Eds.) (2007), Climate Change 2007: The Physical Science Basis. Contribution of Working Group I to the Fourth Assessment Report of the Intergovernmental Panel on Climate Change, Cambridge Univ. Press, Cambridge, U. K.

van Beek, R. (2002), Assessment of the influence of changes in land use and climate on landslide activity in a mediterranean environment, Ph.D. thesis, Utrecht Univ., Utrecht, Netherlands.

van Genuchten, M. T. (1980), A closed-form equation for predicting the hydraulic conductivity of unsaturated soils, Soil Sci. Soc. Am. J., 44, 892-898.

M. F. P. Bierkens and R. J. Brolsma, Department of Physical Geography, Utrecht University, PO Box 80115, NL-3508 TC Utrecht, Netherlands. (m.bierkens@geo.uu.nl; rbrolsma@yahoo.com)

M. T. H. van Vliet, Earth System Science and Climate Change, Wageningen University and Research Centre, PO Box 47, NL-6700 AA Wageningen, Netherlands. (michelle.vanvliet@wur.nl) 